\title{
Helicobacter pylori in dyspeptic patients in Kuwait
}

\author{
D P Britt, M H Barakat, M F Tungekar, S M Painchaud, M Adlouni, K Kern, L Malhas
}

\begin{abstract}
Two hundred and four patients, mainly Arabs, attending for upper gastrointestinal endoscopy at the gastroenterology clinic in Mubarak Al-Kabeer Hospital, Kuwait, were examined for evidence of infection with Helicobacter pylori and associated inflammation. Biopsy specimens of antrum, body, and duodenum; gastric juice; and antral mucosal brushings were investigated by microbiological, cytological, and histopathological methods. Clinical conditions diagnosed at endoscopy included gastritis, gastric ulcer, duodenitis and duodenal ulcer, but half the patients had endoscopically normal gastric and duodenal mucosae. $H$ pylori was detected by one or more of the procedures in at least one specimen from $197(96.6 \%)$ of the patients. Histological and cytological analysis showed equal sensitivity, but bacteriological culture was less reliable. The proportion of positive cases was high, compared with other reported series, which may have been accounted for by the variety of diagnostic techniques used in this study, the selected population (all with gastrointestinal symptoms) or genetic or environmental predisposing factors peculiar to the sample population.
\end{abstract}

Helicobacter pylori has engendered considerable interest among gastroenterologists and microbiologists since the description and isolation of the organism by Warren and Marshall in $1983^{1}$ and their proposal of a causative role for it in type $B$ gastritis and possibly other conditions. Lee and Hazell, in a review of the ecology of the organism, indicated that there was a variation in gastric colonisation rates between populations of different ethnic origins, ranging from $38 \%$ for Caucasians to $90 \%$ for Arabs, but the latter figure was based on a sample of only 21 subjects. ${ }^{2}$

This study was undertaken to assess the prevalence of $H$ pylori in patients presenting with gastrointestinal symptoms in Kuwait and to see if the presence of the organism could be correlated with specific pathological condition(s). Symptoms of dyspepsia are a common reason for patients seeking medical attention in Kuwait.

\section{Methods}

Two hundred and four adults referred for upper gastrointestinal endoscopy were randomly selected for this study. Inclusion in the study was based on elective endoscopy scheduled by the referring clinician for dyspeptic symptoms for which a diagnosis was sought. Patients were excluded if they had a recent history of upper gastrointestinal bleeding or if there was evidence of active upper gastrointestinal bleeding or gastric malignancy at endoscopy. The resulting population contained subjects from 18 countries; the three largest national groups comprised two thirds of the total-Kuwaitis $(n=57)$, Jordanians, $(n=44)$ and Egyptians $(n=34)$. Other Arabs ( $\mathrm{n}=36$ ) were from Iraq, Lebanon, Saudi Arabia, Syria and Yemen. There were 20 Asians from the Indian subcontinent, five other Asians, four Eurasians, three Africans and one Briton. The ages ranged from 14 to 80 , but most were in their middle years from 30 to 60 with a mean age, overall, of 41 . There were 119 men and 85 women.

Endoscopy was performed early in the morning after a minimum of six hours fasting. Patients were prepared by topical xylocaine anaesthesia of the throat and sedation with Diazepam intravenously. Olympus $P_{3}$ GIF endoscopes were used after having been sterilised with cidex (Surgikos) and rinsed with sterile saline. Gastric juice was suctioned and collected in a mucus trap bottle fixed between the scope and the suction apparatus.

Multiple biopsy specimens from antrum, body, and duodenum were obtained in the usual way and immediately transferred to the proper containers for bacteriological and histological processing. After brushing the distal antrum at a non-traumatised site the brush tip was protected and the scope was withdrawn with the brush in position. Details of the clinical and endoscopic findings were not made known to the bacteriologist and histopathologist.

Biopsy specimens were transferred directly to a few drops of sterile $20 \%$ glucose solution, then ground with a micro tissue grinder, and the suspension used to inoculate three culture plates to prepare Gram stained smears and to inoculate a tube of urea broth incubated for up to 24 hours in a water bath at $37^{\circ} \mathrm{C}$. Culture plates used were: (i) a human blood agar plate for aerobic incubation; (ii) a blood agar plate reinforced with IsoVitalex (BBL 
Table 1 Conditions diagnosed at endoscopy

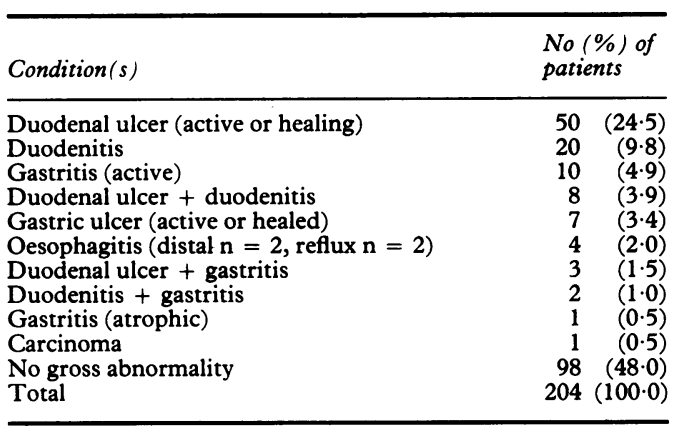

Microbiology Systems, Cockeysville, Maryland, USA) and supplemented with amphotericin $2 \mathrm{mg} / \mathrm{l}$, vancomycin $6 \mathrm{mg} / \mathrm{l}$, and nalidixic acid $20 \mathrm{mg} / 1 ;^{3}$ and (iii) a chocolated blood agar plate with the same additions. The enriched or selective media were incubated in an anaerobic jar with Campy-paks (BBL Microbiology Systems) to provide microaerophilic conditions and were examined after four and six days. The aerobic blood agar plate was read after 24 and 48 hours of incubation. All three plates were incubated at $37^{\circ} \mathrm{C}$

Specimens for cytological examination were used to make up to six impression smears for staining by the Papinacolau, haematoxylin and eosin, Giemsa, Warthin-Starry and half Gram techniques. ${ }^{4}$ Cytology smears made from the suspensions prepared for microbiological culture proved unsatisfactory and were discontinued after the first 49 patients when the impression smear technique was introduced.

Specimens for histopathological analysis were fixed in $10 \% \mathrm{v} / \mathrm{v}$ buffered formalin and routinely processed. Sections were cut at $5 \mu \mathrm{m}$ and stained by haematoxylin and eosin, Warthin-Starry, or half Gram and examined for the presence of inflammation and $H$ pylori.

The inflammatory reaction was assessed and categorised as follows:

(i) Active inflammation, characterised by the presence of neutrophils either in the lamina propria or in the epithelial cells, leading to their focal destruction. Cells of the surface and pit epithelium (and enterocytes in the case of duodenum) showed degenerative changes with ruffled luminal borders. Eosinophils and lymphocytes, commonly in aggregates, were also present.

(ii) Resolving acute inflammation, showing evidence of epithelial regeneration with inflammatory changes as in (i) but much milder. (iii) Healed inflammation, showing mucosal atrophy with fibrous replacement of glandular epithelium. In the duodenum the main changes were partial atrophy of villi. There

Table $2 \quad H$ pylori detected by culture

\begin{tabular}{llll}
\hline Specimen & $\begin{array}{l}\text { Number } \\
\text { cultured }\end{array}$ & $\begin{array}{l}\text { Number positive } \\
\text { for H pylori }\end{array}$ & $\begin{array}{l}\text { Percentage positive } \\
\text { for H pylori }\end{array}$ \\
\hline Antral biopsy & 203 & 130 & $64 \cdot 0$ \\
Body biopsy & 204 & 121 & $59 \cdot 3$ \\
Duodenal biopsy & 204 & 29 & $14 \cdot 2$ \\
Gastric juice & 197 & 7 & $3 \cdot 6$ \\
Gastric brushings & 159 & 115 & $72 \cdot 3$ \\
\hline
\end{tabular}

were no noticeable features of active inflammatory damage.

Metaplastic epithelial changes were also noted in both gastric and duodenal biopsy specimens.

Gastric juice aspirated before biopsy was transferred to a dry, sterile container. Up to $20 \mathrm{ml}$ of the fluid was centrifuged and the deposit used to inoculate culture plates as for biopsy samples. Smears were prepared from the deposit for Gram staining and staining by other cytological procedures. The $\mathrm{pH}$ of the supernatant was noted.

Antral mucosal brushings were inoculated directly from the brush on to three culture plates as for biopsy and gastric juice samples. Residual material was used to prepare smears for cytological investigations.

Aerobic blood agar plates were assessed for rapidly growing contaminating micro-organisms. Isolates on the enriched or selective media incubated microaerophilically were identified as $H$ pylori on the basis of growth characteristics, colonial morphology, Gram stain reaction, and cellular morphology, rapid urease production, catalase and oxidase reactions, and $\mathrm{H}_{2} \mathrm{~S}$ production detected by lead acetate strips. Culture plates were used within one week of preparation and stored at $4^{\circ} \mathrm{C}$.

Disc diffusion testing of susceptibility to a range of antimicrobial agents was carried out on 263 isolates from 113 patients. Tests, based on the modified Kirby-Bauer procedure, were performed as recommended, ${ }^{5}$ except that reinforced blood agar (without antimicrobial supplementation) replaced Mueller-Hinton agar and the plates were incubated for four days in microaerophilic conditions.

\section{Results}

\section{CLINICAL}

Endoscopic diagnoses are shown in table 1. The four patients with reflux or distal oesophagitis had no observable lesions in the stomach or duodenum. There were thus 102 patients $(50 \%)$ without endoscopic abnormalities in these sites. The case of carcinoma was diagnosed retrospectively by histopathological analysis.

\section{MICROBIOLOGICAL FINDINGS}

Table 2 shows results of cultures for $H$ pylori. Of the 204 patients, $162(79.4 \%)$ gave positive cultures in one or more of the specimens. Few biopsy specimens produced any growth on the aerobic blood agar plates, but gastric brush samples frequently yielded heavy growth of throat commensals, predominantly $\alpha$ haemolytic and non-haemolytic streptococci. These contaminants were much suppressed in the selective conditions provided for $H$ pylori culture. Gastric juice samples occasionally yielded heavy growth of similar organisms in aerobic culture, but most often gave no growth or only a few colonies. Heavy growth of these contaminating organisms most often occurred in specimens with high $\mathrm{pH}$ values; four of seven gastric juice samples giving positive $H$ pylori culure were of $\mathrm{pH} 6.0$ or 
Table 3 Percentage agreement between direct Gram stain smear and culture

\begin{tabular}{llll}
\hline Specimen & $\begin{array}{l}\text { Both smear and } \\
\text { culture plus or minus }\end{array}$ & $\begin{array}{l}\text { Smear plus/ } \\
\text { culture minus }\end{array}$ & $\begin{array}{l}\text { Smear minus/ } \\
\text { culture plus }\end{array}$ \\
\hline Antral biopsy & 55 & 17 & 28 \\
Body biopsy & 50 & 13 & 37 \\
Duodenal biopsy & 82 & 3 & 15 \\
Gastric juice & 56 & 41 & 3 \\
\hline
\end{tabular}

above. The $\mathrm{pH}$ of most of the samples (76\%) lay between 1.05 and 2.96 ; only $17(9 \%)$ were $7 \cdot 0$ or higher.

Examination of Gram stained smears prepared from biopsy specimens at the time of culture tended to be less sensitive as a means of detecting $H$ pylori than culture. The reverse, however, was true for grastric juice samples. Examination of a few Gram stained smears prepared from mucosal brush samples indicated that direct microscopy is a valuable adjunct to culture in the investigation of these specimens. Table 3 summarises the results of direct microscopic examination compared with culture results. duodenal biopsy specimens showed positive for urease but were negative on culture.

In the tests for antibiotic susceptibility (table 4) inhibition zones of a size which would indicate sensitivity in standard conditions were achieved regularly with $\beta$-lactams, aminoglycosides, erythromycin, tetracycline and chloramphenicol. Isolates were uniformly "resistant" to the $\mathbf{3 0} \mathrm{mg}$ nalidixic acid disc, as was to be expected; most isolates were not inhibited by colistin or polymyxin B. More variable results were obtained with clindamycin, metronidazole, and novobiocin.

\section{CYTOLOGICAL FINDINGS}

Detection of bacteria morphologically typical of $H$ pylori by cytological procedures was a reliable diagnostic procedure in well prepared smears. Table 5 summarises results of these investigations. In table 6 , a comparison is made between the detection rate of presumptive $H$ pylori in gastric brush cytology and histological examination of antral biopsy specimens in 177

Table 4 Antibiotic susceptibilities of $H$ pylori isolates *

\begin{tabular}{|c|c|c|c|c|c|}
\hline \multirow[b]{2}{*}{ Antibiotic } & \multirow{2}{*}{$\begin{array}{l}\text { Concentration } \\
\text { in disc }\end{array}$} & \multicolumn{4}{|c|}{ Number of isolates } \\
\hline & & Tested & Sensitive & Intermediate & Resistant \\
\hline $\begin{array}{l}\text { Ampicillin } \\
\text { Augmentin } \\
\text { Carbenicillin } \\
\text { Cefazolin } \\
\text { Cephalothin } \\
\text { Cefuroxime } \\
\text { Streptomycin } \\
\text { Kanamycin } \\
\text { Neomycin } \\
\text { Gentamicin } \\
\text { Tobramycin } \\
\text { Amikacin } \\
\text { Erythromycin } \\
\text { Novobiocin } \ddagger \\
\text { Tetracycline } \\
\text { Clindamycin } \\
\text { Chloramphenicol } \\
\text { Polymyxin B } \ddagger \\
\text { Colistin } \ddagger \\
\text { Metronidazole } \\
\text { Nalidixic acid }\end{array}$ & $\begin{array}{c}10 \mu \mathrm{g} \\
30 \mu \mathrm{g} \dagger \\
100 \mu \mathrm{g} \\
30 \mu \mathrm{g} \\
30 \mu \mathrm{g} \\
30 \mu \mathrm{g} \\
10 \mu \mathrm{g} \\
30 \mu \mathrm{g} \\
30 \mu \mathrm{g} \\
10 \mu \mathrm{g} \\
10 \mu \mathrm{g} \\
30 \mu \mathrm{g} \\
15 \mu \mathrm{g} \\
30 \mu \mathrm{g} \\
30 \mu \mathrm{g} \\
2 \mu \mathrm{g} \\
30 \mu \mathrm{g} \\
300 \mathrm{U} \\
10 \mu \mathrm{g} \\
5 \mu \mathrm{g} \\
30 \mu \mathrm{g}\end{array}$ & $\begin{array}{r}132 \\
41 \\
33 \\
27 \\
210 \\
214 \\
14 \\
12 \\
113 \\
65 \\
12 \\
27 \\
190 \\
74 \\
72 \\
26 \\
96 \\
147 \\
160 \\
42 \\
263\end{array}$ & $\begin{array}{r}132 \\
40 \\
33 \\
27 \\
209 \\
213 \\
14 \\
12 \\
112 \\
65 \\
12 \\
27 \\
188 \\
55 \\
72 \\
9 \\
96 \\
17 \\
3 \\
16 \\
0\end{array}$ & $\begin{array}{r}0 \\
0 \\
0 \\
0 \\
0 \\
0 \\
0 \\
0 \\
0 \\
0 \\
0 \\
0 \\
0 \\
18 \\
0 \\
5 \\
0 \\
7 \\
0 \\
1 \\
0\end{array}$ & $\begin{array}{r}0 \\
1 \\
0 \\
0 \\
1 \\
1 \\
0 \\
0 \\
1 \\
0 \\
0 \\
0 \\
2 \\
1 \\
0 \\
12 \\
0 \\
123 \\
157 \\
25 \\
263\end{array}$ \\
\hline
\end{tabular}

*Interpretation of zone diameters according to Barry and Thornsberry (1985).5

$\dagger$ Amoxycillin $20 \mu \mathrm{g}+$ Clavulanic acid $10 \mu \mathrm{g}$.

$\ddagger$ Interpretation of zone diameters according to BBL product information, Becton Dickinson 1986.

Direct urease tests on biopsy samples were less reliable in our hands than in other pub-lished studies. More positive results were obtained with biopsy specimens from the antrum ( 54 of $203,26.6 \%$ ) than from other sites. Of these, 16 were negative on culture. Only 28 of 204 stomach body biopsy specimens showed positive for urease $(13.7 \%)$, including nine negative on culture. Four of $204(2 \%)$

Table 5 Detection of Helicobacter-like organisms (HLO) in biopsy imprints, gastric juice, and gastric mucosal brushings by cytology

\begin{tabular}{llcl}
\hline Specimen & $\begin{array}{l}\text { Number } \\
\text { examined }\end{array}$ & $\begin{array}{l}\text { Positive } \\
\text { for HLO }\end{array}$ & $\begin{array}{l}\text { Percentage positive } \\
\text { for HLO }\end{array}$ \\
\hline Antral biopsy & 147 & 123 & $83 \cdot 7$ \\
Body biopsy & 147 & 100 & $68 \cdot 0$ \\
Duodenal biopsy & 145 & 23 & $15 \cdot 9$ \\
Gastric juice & 202 & 27 & $13 \cdot 4$ \\
Gastric brushings & 177 & 169 & 95.5 \\
\hline
\end{tabular}

^Only technically satisfactory specimens were included. patients. These findings confirm and extend the results reported earlier. ${ }^{4}$

In 145 cases satisfactory samples allowed comparison to be made between gastric mucosal brush smears and smears prepared from gastric biopsy imprints. In $127(87.6 \%)$ of these the findings coincided: 122 showed the typical spiral bacteria, five were negative. In 15 of the remaining 18 cases, the organisms were seen only in smears of gastric brushings.

\section{HISTOPATHOLOGICAL FINDINGS}

Presumptive $H$ pylori was shown in most of the gastric biopsy specimens, but only in few of the duodenal biopsy specimens examined (table 7). Pyloric metaplasia was observed in 34 of 176 duodenal biopsy specimens. In 11 of these cases, Helicobacter-like organisms were present in sections; the organisms were not found in duodenal sections in the absence of 
Table 6 Helicobacter-like organisms detected by cytological smear of gastric brush material and histological section of antral biopsy specimen

\begin{tabular}{lrrr}
\hline & $\begin{array}{c}\text { Number (\%) of } \\
\text { cases }^{\star}\end{array}$ \\
\hline $\begin{array}{l}\text { Gastric brush smear positive/antral biopsy } \\
\text { section positive }\end{array}$ & 165 & $(93 \cdot 2)$ \\
$\begin{array}{l}\text { Gastric brush smear positive/antral biopsy } \\
\text { section negative }\end{array}$ & 6 & $(3 \cdot 4)$ \\
$\begin{array}{l}\text { Gastric brush smear negative/antral biopsy } \\
\text { section positive }\end{array}$ & 3 & $(1 \cdot 7)$ \\
$\begin{array}{l}\text { Gastric brush smear negative/antral biopsy } \\
\text { section negative }\end{array}$ & 3 & $(1 \cdot 7)$ \\
\hline 177 cases were satisfactory for comparison. & & &
\end{tabular}

Table 7 Helicobacter-like organisms in biopsy sections

\begin{tabular}{lrc}
\hline & \multicolumn{2}{c}{$H L O$ positive* } \\
\cline { 2 - 3 } Biopsy site & \multicolumn{2}{c}{ Number (\%) } \\
\hline Antrum & 187 & $(94 \cdot 9)$ \\
Stomach body & 152 & $(77 \cdot 2)$ \\
Duodenum & 11 & $(5 \cdot 6)$ \\
One or more & 188 & $(95 \cdot 4)$ \\
\hline
\end{tabular}

«Specimens from 197 of the 204 cases submitted were satisfactory for HLO detection.

pyloric metaplasia in this series. Intestinal metaplasia was observed in one antral and one stomach body biopsy specimen. Both of these were positive for Helicobacter-like organisms.

Close correlation was found between results obtained with cytological smears of gastric brushings and sections from antral biopsies (table 6).

Inflammation was usually associated with the presence of Helicobacter-like organisms in biopsy sections (table 8 ).

\section{Discussion}

Helicobacter pylori was detected in 197 of 204 $(96.6 \%)$ patients in this series of dyspeptic subjects attending for upper gastrointestinal endoscopy. Detection of the organism was most successful in histological sections of antral biopsy specimens and in cytological smears prepared from antral mucosal brushings. Gastric brushing was shown to be a useful procedure in the diagnosis of $H$ pylor $i$ infection and, as a less invasive technique, is to be preferred to biopsy. Culture, which allowed identification of the organisms by standard bacteriological methods, was less sensitive, but strict criteria were applied before cultures were judged positive. Thus isolates which failed to grow on subculture and could not be confirmed biochemically were considered not to be Heli-

Table 8 Association between degrees of inflammation and Helicobacter-like organisms in biopsy sections

\begin{tabular}{llll}
\hline Type of inflammation & Number of cases & HLO positive & HLO negative \\
\hline Active & 68 & 68 & 0 \\
Resolving & 79 & 76 & 3 \\
Healed & 31 & 29 & 2 \\
No significant inflammation/ & 9 & 5 & 4 \\
repair & 9 & & \\
\hline
\end{tabular}

* Specimens from 187 of the 204 cases submitted were satisfactory for evaluation of inflammatory reactions. cobacter in spite of favourable cultural and morphological evidence.

Antral biopsy specimens gave a greater yield of positive cultures than specimens from other sites, but the highest percentage of positive cultures was obtained with gastric brushings, perhaps because this technique permits wider sampling and thereby overcomes problems of patchy distribution of the organisms. Duodenal biopsy specimens were more frequently found positive on culture and in cytological preparations than on histological examination. Ten of the 29 culture positive duodenal biopsy samples showed gastric metaplasia histologically. Others may have been asssociated with gastric metaplasia not detected in sections because of the restricted and localised distribution of gastric epithelium in the duodenum. ${ }^{6}$ Alternatively, cultures might have been positive through contamination of the specimens with gastric mucus. Gastric juice was unsatisfactory for culture, although spiral bacteria morphologically typical of $H$ pylor $i$ were often seen in Gram stained smears prepared from centrifuged deposits. Rapid neutralisation of the fluid after collection might improve chances of successful isolation of the organisms.

The direct urease test on biopsy material gave disappointing results with a sensitivity of only $27 \%$ in antral biopsy specimens compared with well over $90 \%$ in other studies. ${ }^{7}$ Our methodology of first grinding the tissue in $20 \%$ glucose and adding a drop of the suspension to urea broth severely reduced the sensitivity of this procedure.

Antibiotic susceptibility tests were carried out to detect strain differences in the isolates, not as a guide to chemotherapy in view of the non-standard test procedure. Results showed a large measure of uniformity and correlated well with data compiled from earlier studies. ${ }^{8}$ Clindamycin and metronidazole were most effective in discriminating between strains.

The high rate of detection of $H$ pylori in this study may have been due to the genetic predisposition of the ethnic groups (mainly Arabs) included in the patient population or to local environmental, including dietary, factors. The sample population was selected, however, al presenting with gastrointestinal symptoms, so the results cannot be applied to the general population of the area. The combination of detection techniques used has also increased the number of positive cases found. Although on gross endoscopic examination, the gastroduodenal mucosa of $50 \%$ of the patients seemed to be "normal" histologically, $H$ pylori-like organisms with associated inflammation were common (table 9). Furthermore, in 63 of the patients without gross abnormality the organism was isolated from the antral or stomach body biopsy specimen and identified specifically by bacteriological means.

In attempting to correlate endoscopic diagnosis with laboratory findings (table 9), a clear cut association between duodenal ulcer and duodenitis (the two most frequently recognised pathological conditions) and the presence of $H$ pylori was apparent. Usually an inflammatory 
Table 9 Associations between endoscopic diagnoses and laboratory findings

\begin{tabular}{|c|c|c|c|c|c|c|c|c|}
\hline \multirow[b]{2}{*}{ Endoscopic diagnosis (of patients) } & \multicolumn{4}{|c|}{ Gastric mucosa } & \multicolumn{4}{|c|}{ Duodenal mucosa } \\
\hline & PHP & $P H P+I$ & $I$ & $N A$ & PHP & $P H P+I$ & $I$ & $N A$ \\
\hline $\begin{array}{l}\text { Duodenal ulcer (50) } \\
\text { Duodenitis (20) } \\
\text { Gastritis, active (10) } \\
\text { Duodenal ulcer + duodenitis (8) } \\
\text { Gastric ulcer (7) } \\
\text { Oesophagitis (4) } \\
\text { Duodenal ulcer + gastritis (3) } \\
\text { Duodenitis + gastritis (2) } \\
\text { Gastritis, atrophic (1) } \\
\text { Carcinoma (1) } \\
\text { No gross abnormality (98) }\end{array}$ & $\begin{array}{r}5 \\
2 \\
2 \\
1 \\
2 \\
0 \\
0 \\
0 \\
1 \\
1 \\
11\end{array}$ & $\begin{array}{r}45 \\
18 \\
7 \\
7 \\
5 \\
4 \\
3 \\
1 \\
0 \\
0 \\
82\end{array}$ & $\begin{array}{l}0 \\
0 \\
0 \\
0 \\
0 \\
0 \\
0 \\
0 \\
0 \\
0 \\
0 \\
3\end{array}$ & $\begin{array}{l}0 \\
0 \\
1 \\
0 \\
0 \\
0 \\
0 \\
1 \\
0 \\
0 \\
2\end{array}$ & $\begin{array}{r}5 \\
3 \\
1 \\
1 \\
0 \\
0 \\
0 \\
0 \\
0 \\
0 \\
10\end{array}$ & $\begin{array}{r}18 \\
6 \\
0 \\
2 \\
3 \\
1 \\
1 \\
1 \\
0 \\
1 \\
11\end{array}$ & $\begin{array}{r}19 \\
7 \\
4 \\
2 \\
1 \\
2 \\
2 \\
1 \\
1 \\
0 \\
47\end{array}$ & $\begin{array}{r}8 \\
4 \\
5 \\
3 \\
3 \\
1 \\
0 \\
0 \\
0 \\
0 \\
30\end{array}$ \\
\hline
\end{tabular}

PHP = presumptive (or confirmed) $H$ pylori $\mathrm{I}=$ inflammation detected histologically; NA = no abnormality .

reaction was also detectable. This association, however, was hardly more remarkable than that between the presence of the organism with inflammation and no gross abnormality. The clinical importance of the presence of these organisms might be discounted if the patients without gross abnormality had been asymptomatic. In the circumstances our findings are consistent with the view that $H$ pylori serves as a predisposing factor in gastroduodenal pathology and may serve as an early indicator of serious impending disease.

We thank Dr George Araj and his colleagues in the microbiology laboratory of Mubarak A1-Kabeer hospital for providing bench space for setting up the cultures. This work was supported by grant MH005 from Kuwait University.
1 Warren JR, Marshall B. Unidentified curved bacilli on gastric epithelium in active chronic gastritis. Lancet gastric epithel

2 Lee A, Hazell SL. Campylobacter pylori in health and disease: an ecological perspective. Microbial Ecology in Health \& Disease 1988; i: 1-16.

3 Goodwin CS, Blincow ED, Warren JR, Waters TE, Sanderson CR, Easton L. Evaluation of cultural techniques for isolating Campylobacter pyloridis from endoscopic biopsies of gastric musosa. J Clin Pathol 1985; 38:1127-31.

4 Britt DP, Painchaud SM, Tungekar MF, et al. Detection of Helicobacter pylori in gastric brushings. Trans Roy Soc Trop Med Hyg 1990;84:581-2.

5 Barry AL, Thornsberry C. Susceptibility tests: diffusion test procedures. In: Lennette EH, Balows A, Hansler WJ, Shadomy HJ, eds. Manual of clinical microbiology. 4th Shadomy HJ, eds. Manual of clinical microbiology. 4th
ed. Washington: American Society for Microbiology

6 Graham DY. Campylobacter pylori and peptic ulcer disease. Gastroenterology 1989;96:615-25.

7 McNulty CAM, Dent JC, Uff JS, Gear MWL, Wilkinson SP. Detection of Campylobacter pylori by the biopsy urease test: an assessment in 1445 patients. Gut 1989; 30:1058-62.

8 Bayerdorffer E, Ottenjann R. The role of antibiotics in Campylobacter pylori associated peptic ulcer disease. Scand J Gastroenterol 1988;23 (suppl 142):93-100. 